\title{
Fertilizer Usage and Land Productivity in Intensively Cultivated Vegetable Farming Systems in Sri Lanka: An Analysis Based on a Questionnaire Survey
}

\author{
H.A.N. Upekshani ${ }^{1}$, R.S. Dharmakeerthi ${ }^{2 *}$, P. Weerasinghe ${ }^{3}$ and W.S. Dandeniya ${ }^{2}$
}

Postgraduate Institute of Agriculture, University of Peradeniya, Sri Lanka

\begin{abstract}
Vegetable cultivation in Sri Lanka is an intensive and highly commercialized system. Since, vegetables are heavy nutrient feeders that produce high biomass within a short period, management of fertilizers and amendments are critical for sustainable production. The objective of this study was to assess the fertilizer and amendment usage by intensively vegetable cultivating farmers in Sri Lanka and identify the relationship between farmer practices and their productivity using a questionnaire survey. Study was conducted with randomly selected 100 farmers each from Nuwara Eliya (NE) and Marassana (M) regions. Data were obtained on relative use of inorganic fertilizers, organic amendments and liming materials, with respect to the current recommendations. The vegetable cultivating systems of the two regions were identified as vegetable-potato-vegetable and vegetablepaddy-vegetable for NE and $M$, respectively. The productivity of crops cultivated in NE was higher than that of $M$. While about $25 \%$ and $67 \%$ of farmers in NE and $M$, respectively, used synthetic fertilizers more than the recommended level, about 66\% (NE) to 99\% (M) farmers used less than $50 \%$ of the recommended organic manure quantities for their vegetable crops. We attributed these differences to other crops included in the rotation, availability and high cost of organic fertilizers, and the value of crops, in addition to the cash subsidy given for synthetic fertilizers. Productivity of fields in $M$, where moisture stresses are more common, appeared not related to the relative quantity of fertilizer or amendments used. However, the productivity was maximized around $70-90 \%$ of recommended level of fertilizers among farmers in NE. We concluded that site-specific fertilizer best management practices need to be introduced to intensively cultivating farmers in Sri Lanka, in order to increase and sustain productivity.
\end{abstract}

Keywords: Soil amendments, fertilizer usage, intensive vegetable cultivation, crop productivity

\section{INTRODUCTION}

Vegetable cropping systems in the world are characterized by intensive and repeated tillage, over or under fertilization, and limited crop rotation with short lived crops (Alliaume et al., 2013, Willekens et al., 2014). Vegetables are heavy nutrient feeders (Wijewardhana, 2000a). Owing to the characteristic shallow root system, they obtain nutrients from a small volume of

\footnotetext{
1 School of Agriculture, Department of Agriculture, Kundasale, Sri Lanka

2 Department of Soil Science, Faculty of Agriculture, University of Peradeniya, Peradeniya, Sri Lanka

3 Horticultural Crop Research and Development Institute, Department of Agriculture, Gannoruwa, Sri Lanka

* Corresponding author.dharmakeerthirs@gmail.com
} 
soil but remove higher amount of plant nutrients from the cropping field through high quantity of biomass yield that is produced within 2-4 months (Sooriyagoda et al., 2012). Therefore, constant application of organic and/or inorganic fertilizers is essential to maintain high productivity. The total land area under vegetable cultivation in Sri Lanka is 90,518 ha in 2015, of which $35 \%$ is in the upcountry (Anon, 2016). Vegetable cultivations in up-country in Sri Lanka is intensive and highly commercialized, because income derived from the vegetable production is higher when compared to other cultivations (Wijewardhana, 2000b). Several studies have reported that the usage of fertilizers in upcountry vegetable cultivation was higher than the recommended rates (Wijewardhana and Amarasiri, 1993;1997, Wijewardhana et al., 2001, Wijewardhana., 2001a, b and c). Excessive use of chemical fertilizers not only increases the cost of production, but also contributes to the environmental quality (Ariyapala and Nissanka, 2006). Other than that soil and drinking water quality of the wells also had been affected with the intensive vegetable cultivations in up-country Sri Lanka (Kuruppuarchchi, 2010; Wijewardhana et al., 2001). However, indiscriminate use of fertilizers is being continued in these cropping systems throughout the year with least consideration on soil quality, partly due to the low cost of subsidized chemical fertilizer. Studies on fertilizer usage in intensively cultivated vegetable soils have been conducted during the period when the material subsidy on chemical fertilizers have been in place (Weerahewa et al., 2010). In addition to the references quoted above, Kendaragama (2006) studied the fertilizer usage in different cropping systems in Sri Lanka when the "Kethata Aruna" fertilizer material subsidy programs was in place and reported that chemical fertilizer usage for vegetables in upcountry vegetable cropping systems varied from 100 to $425 \%$ of the recommended level. Government policy on fertilizer subsidy changed from a material subsidy to a cash subsidy in 2015 and information on the usage of chemical fertilizer by farmers under this new subsidy scheme is not available. Latheef and Maraikar (2003) observed that continuous organic manure application has resulted nutrient accumulation, particularly available $\mathrm{P}$ in some vegetable cultivating soils and highlighted the need for regular monitoring of organic manure usage and soil quality to sustain the soil fertility. However, to the best of our knowledge there is no published literature on the usage of organic fertilizers in intensively cultivated vegetable cropping systems in Sri Lanka. The objectives of this study were (i) to quantify the fertilizer and amendment usage in intensive vegetable cultivating lands in the mid- and up-country in Sri Lanka under the new cash subsidy program for fertilizer and (ii) to determine the relationship between the farmer fertilizer practices and the productivity of the lands. This was achieved through a questionnaire-based survey conducted using 200 intensively vegetable cultivating farmers from Nuwara Eliya (NE) and Marassana (M) regions.

\section{METHODOLOGY}

\section{Study area}

The study areas were selected from five Agrarian Services Divisions (ASD) in NE (i.e., Nuwara-Eliya, Kandapola, Ragala, Nildandahinna and Mandaramnuwara). In Marasssana, intensively cultivating vegetable farmers are highly concentrated in the up-country and some areas of mid-country in Sri Lanka according to the farmer lists available at ASDs. One hundred farmers each from NE and $\mathrm{M}$ were selected randomly representing Magoda, Meepilimana, Jayawardhanapura, Kande-ela, Kalukale, Palalpathana, Mahakudugala, Kandapola, and Mandaramnuwara villages from NE and Marassana, Damunugolla, Meeruppa, Alekewela, Galagoda, Kirawanagoda, Kandewela and Bawlana villages from M. 
A questionnaire survey was conducted using the selected farmers of these areas in 2017 after introduction of the cash subsidy program. Information on GPS location, crops cultivated, land area, yield, types and the quantities of fertilizers applied both organic and inorganic, the quantities and the forms of liming material application and farmers' perception about the productivity of their lands when compared with neighboring lands were obtained from the farmers for the vegetable cultivating seasons in 2017 (i.e. Yala season and some months in the Maha season). The distribution of the selected farmer fields are given in Figure 1.
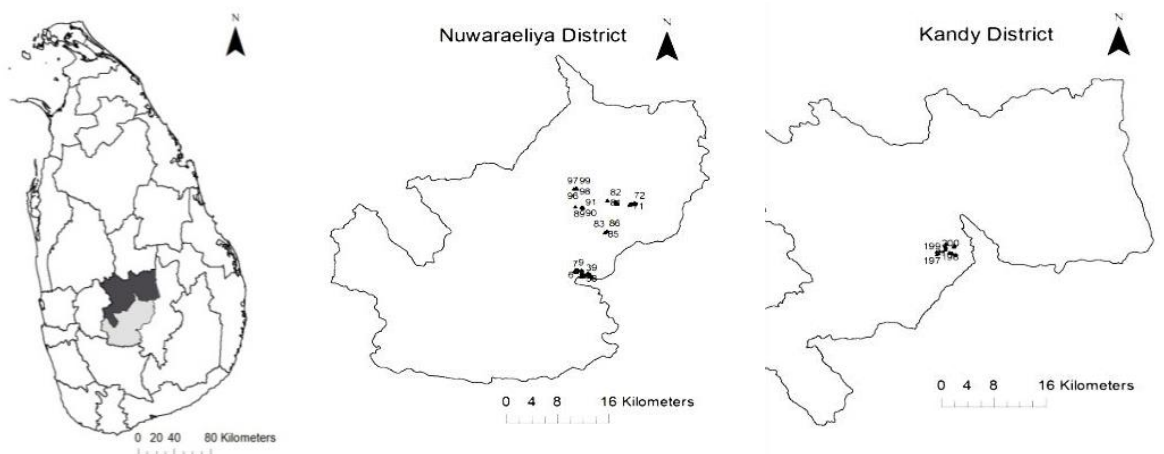

\section{Figure 1. Distribution of the selected farmer fields in Nuwara Eliya and Marassana regions in Nuwara Eliya and Kandy districts in Sri Lanka}

The productivity of the land was calculated separately for each crop by dividing yield data provided by the farmers from the cultivated area and then averaged for the total cultivated land area. Quantities of different liming materials used by farmers were converted into calcium carbonate equivalent using 115 for dolomite and 100 for lime.

The Relative Use (RU) of all fertilizers and amendments was calculated as follows (Kendaragama, 2006).

RU\% $=\underline{\text { Amount of fertilizer/amendment applied to a crop by the farmers }} \times 100$

Amount of fertilizer/amendment recommended to the crop

Since the data on fertilizer quantities applied for each crop were not available with the farmers the total fertilizer applied for the cropping field was divided proportionately based on the land area. Further, two different rates of fertilizer recommendations were assumed for vegetables cultivated in the two regions because there were no crop-wise information available with farmers. However, it was noted that the crop-wise deviations in the DOA recommendations were small for the selected crops except for the $\mathrm{N}$ recommendation for leeks, carrot and bean and only small percent of land extent $(<5 \%)$ had been cultivated with radish and bean crop. Accordingly, it was assumed that DOA recommendation was $330 \mathrm{~kg}$ of urea, $270 \mathrm{~kg}$ of triple super phosphate (TSP) and $200 \mathrm{~kg}$ of muriate of potash (MOP) per ha for carrot, cabbage, leeks, beet and radish cultivated in NE, while the values for tomato, bitter gourd, snake gourd, luffa and beans in M were 220, 270, and $150 \mathrm{~kg} / \mathrm{ha}$, for Urea, TSP and MOP, respectively. The DOA recommendation for organic manure was taken as 10 tons of compost or cow dung and 5 tons of poultry manure per ha per season for vegetable crops. Moreover, the DOA recommendation for the application of liming materials was taken as 1.5 tons/ha/year (Anon, 2007). 


\section{Data analysis}

Data tabulation, processing and calculations were done using Excel 2010. Total or crop-wise productivities and RUs for each fertilizer/amendment were calculated based on the surveyed data. Outliers were identified using 1.5 times the Inter Quartile Range (IQR) and removed from the data set when it became an influential data point in the regression analysis based on Cook's distance. Productivity was regressed against the RUs and a quadratic function was fitted using the Proc REG procedure of the SAS 9.1 system (SAS Systems Inc., 2003). The first derivative of the generated regression models $(P<0.1)$ were used to calculate the RU value at which the maximum productivity has been obtained.

\section{RESULTS AND DISCUSSION}

Soil quality in vegetable cropping systems is seriously threatened by intensive tillage and fertilizer practices and by limited crop rotation (Willekens et al., 2014). The observations made under Sri Lankan conditions were in agreement with the above conditions. According to Wijewardhana (2000b), the agriculture in the up-county in Sri Lanka was intensive and highly commercialized, because high income was derived from vegetable production compared to other crops. Based on the classification used by Kendaragama (2006), the vegetable cultivating systems of study areas were identified as vegetable-potato-vegetable and vegetable-paddy-vegetable for $\mathrm{NE}$ and $\mathrm{M}$, respectively.

According to the farmer survey, paddy cultivation in $\mathrm{M}$ was for the consumption and vegetables are grown as a cash crop. But in NE, both potato and vegetables were mainly for commercial purposes. The type of vegetable predominantly cultivated in the two regions studied were also different. Where high value crops such as carrot, leeks, and cabbage (Wijewardhana, 1993) were common in NE while low value crops such as tomato, snake gourd, and bitter gourd dominated in the vegetable cropping systems in $\mathrm{M}$.

The productivity data we collected during the survey were compared with existing published literature in order to assess the reliability of the information given by farmers during the questionnaire survey. It was observed that our data were more or less similar to those published by the Department of Census and Statistic (Anon, 2015) except for cabbage (Table 1).

\section{Farmers' perception on productivity of their lands}

Farmer practices related to fertilizer usage were often determined by the income level, attitudes of the farmer and government policies on fertilizer subsidy (Weerahewa et al., 2010). Farmers have considered the selection of planting materials is very important on obtaining high yield within a short period of time. Therefore, the tendency was very high to cultivate hybrid varieties. Almost all farmers (95-100\%) were full time vegetable producers and their main source of income was generated from vegetable cultivation. Hence, they did not want to incur losses from the cultivation and tried to maximize the yield. As a result, farmers apply large quantities of chemical fertilizers regardless of the plant nutrient requirements. However, only less than $25 \%$ of the farmers thought that they have achieved the targeted productivity with agro-management practices adopted by them. 
Table 1. Comparison of the productivity declared by the farmers during this survey and the data published by the Department of Census and Statistics in 2015 for the five selected crops in Nuwara Eliya and Marassana regions

\begin{tabular}{llccc}
\hline Region & Vegetable & $\begin{array}{c}\text { \% of } \\
\text { farmers }\end{array}$ & \multicolumn{2}{c}{ Productivity (Mg/ha) } \\
\cline { 3 - 5 } & & & This study & $\begin{array}{c}\text { Census and } \\
\text { Statistics Dept. }\end{array}$ \\
\cline { 3 - 5 } & & & & 24 \\
Nuwara & Carrot & 90 & 24 & 60 \\
Eliya & Cabbage & 50 & 27 & 25 \\
& Leeks & 53 & 19 & 22 \\
& Beet root & 24 & 22 & 20 \\
\hline Marassana & Radish & 10 & 18 & 15 \\
& Tomato & 74 & 18 & 06 \\
& Bitter gourd & 51 & 09 & 8.7 \\
& Beans & 32 & 03 & $13^{*}$ \\
\hline
\end{tabular}

* 2009 data for Kandy district

Based on farmers' perception on the neighboring farmer fields, land productivity was categorized in to three groups; low, moderate and high compared. Out of 100 farmers surveyed in NE, 51 farmers stated that their yield was lower due to many reasons. Only 14 farmers have obtained higher yield with their practices (data not presented). About 50\% of the farmers have cultivated cabbage or carrot, and when compared with the data published by Census and Statistics (2015), the yield of these two crops in NE had been decreased by 45 and $0 \%$, respectively, in the surveyed year (Table 1). According to the 100 farmers surveyed in M, 35 farmers indicated that they have lower yield compared to the others, while only 22 farmers thought that they have higher yields. Therefore, it appears that current soil management practices do not help majority of the farmers in these regions to achieve target yields.

\section{Usage of fertilizers and amendments}

Observations made on current farmer practices displayed the reality of fertilizer usage and the productivity of the vegetable cultivation systems of up county areas. The RU value is an indicator which reflects the status of fertilizer and amendment application by farmers (Kendaragama, 2006). When the RU value exceeded 100\%, farmers apply fertilizers or amendments more than the DOA recommended level (Anon, 2007) while the reverse was true when RU was less than $100 \%$. We allowed $\pm 10 \%$ deviation to the recommended level in order to assess the over and under application of fertilizers and amendments (Table 2). According to this analysis only less than $12 \%$ of the farmers applied the recommended levels $(100 \pm 10 \%)$ of fertilizers or amendments in the two surveyed regions. While about $25 \%$ of the of farmers in NE used chemical fertilizers more than the DOA recommendation, about $67 \%$ of the farmers in $\mathrm{M}$ over applied chemical fertilizers. The maximum RU values for chemical fertilizers recorded by a single farmer in NE and $\mathrm{M}$ were $541 \%$ and $886 \%$, respectively. Number of reasons could be the differences in over application fertilizer in the two regions. Vegetable cultivation being the main income source of farmers in up-country region (Wijewardena, 2000b), excessive fertilizers application is a common trend in upcountry farmers anticipating higher yields (Sooriyagoda et al., 2012; Wijewardhana, 1993). 
Table 2. Number of farmers in Nuwara Eliya and Marassana regions categorized according to relative use (RU) of fertilizers/amendments

\begin{tabular}{|c|c|c|c|c|c|c|c|}
\hline \multirow{2}{*}{ Region } & \multirow{2}{*}{$\begin{array}{l}\mathbf{R U}^{\dagger} \\
\text { Category }\end{array}$} & \multicolumn{6}{|c|}{ Number of farmers ${ }^{\ddagger}$} \\
\hline & & Total CF & Total OF & Urea & MOP & TSP & Lime \\
\hline \multirow{4}{*}{$\begin{array}{l}\text { NuwaraEliya } \\
(n=100)\end{array}$} & $>110 \%$ & 25 & 13 & 51 & 33 & 37 & 16 \\
\hline & $110-90 \%$ & 12 & 7 & 2 & 2 & 11 & 9 \\
\hline & $<75 \%$ & 56 & 79 & 40 & 52 & 50 & 71 \\
\hline & $<50 \%$ & 43 & 66 & 30 & 30 & 50 & 64 \\
\hline \multirow{4}{*}{$\begin{array}{l}\text { Marassana } \\
(n=100)\end{array}$} & $>110 \%$ & 67 & 0 & 66 & 41 & 49 & 14 \\
\hline & $110-90 \%$ & 8 & 0 & 9 & 5 & 6 & 1 \\
\hline & $<75 \%$ & 20 & 100 & 21 & 51 & 38 & 81 \\
\hline & $<50 \%$ & 11 & 99 & 12 & 23 & 38 & 69 \\
\hline
\end{tabular}

However, Wijewardhana (2001a) observed that the heavy fertilization has not resulted in higher productivity as also observed by us. Farmers in NE cultivate potato in the Maha season (Kandaragama, 2006) and they tend to pay more attention to high income generating potato crop than the other vegetable crop. However, since our objective was to study the fertilizer and amendment usage in vegetable cultivation fields, we did not collected data on fertilizer usage for potato cultivated lands in NE and for rice cultivated lands in $\mathrm{M}$. In addition to low income from their vegetable crops, the organic matter content and available nutrient contents in vegetable cultivating areas in $\mathrm{M}$ were also poor compared to that of soils in the NE (Senarath and Dasanayaka, 1999; Dasanayaka and Hettiarachchi, 1999). Low soil fertility too could have tended farmers in $\mathrm{M}$ to rely on higher doses of chemical fertilizers in order to obtain the targeted yields, as observed by Chen et al., (2004) in production agricultural systems in China.

About 50 to $70 \%$ of the vegetable cultivating farmers in the two regions have applied more Urea than the recommended levels while about 30 to $50 \%$ of the farmers applied MOP and TSP more than the recommended level (Table 2). Interestingly, high \% of farmers (50\%) applied less than $50 \%$ of the recommended levels of $\mathrm{P}$ fertilizers unlike for $\mathrm{N}$ and $\mathrm{K}$ fertilizers. Wijewardhana (1999a,b; 2000b) have suggested that application of P and K could be easily reduced by $50 \%$ of the recommendation, when poultry manure is applied at 10 ton/ha in up-country vegetable cultivating areas. Since vegetable cultivating soils in the up-country region have accumulated levels of P (Kendaragama et al., 2001), DOA make farmers aware on this important fact through farmer awareness programs. Whether the lower usage of $\mathrm{P}$ fertilizers is due to the farmer awareness or not needs to be ascertained in a future study.

Contrary to common belief, number of farmers that over applied organic fertilizer was only $13 \%$ and $0 \%$ for $\mathrm{NE}$ and $\mathrm{M}$, respectively. About $99 \%$ of the farmers in $\mathrm{M}$ and $66 \%$ in $\mathrm{NE}$ applied less than $50 \%$ of the recommended levels of organic fertilizers to their vegetable crops. However, our findings contradict with observations made by others where they reported that large amount of cattle and poultry manure are used by the up-country farmers together with high rates of chemical fertilizer (Wijewardena, 1993; Maraikar et al.,1996; 
2000a; Ariyapala and Nissanka, 2006). This may be due to the fact that we did not account for the fertilizers or amendments applied by farmers for potato or rice in these vegetable cropping systems. However, the level of inorganic fertilizer applied by the farmers to potato and vegetables was two to three times higher than the DOA, recommendation (Wijewardhana, 1995). According to Kendaragama (2006), the RU of chemical fertilizer usage in rice cultivation at Marassana was $297 \%$. The very low usage of organic fertilizers in $\mathrm{M}(<15 \%$ of the recommended level) could be due to low availability and high cost of the fertilizers.

\section{Land productivity in relation to fertilizer and amendment usage}

It is expected that crops will respond positively to added fertilizers or amendments, so that the farmers can achieve the yield goals provided that the other factors are at optimum level for crop growth. The calculated RUs for different inputs were related to the total productivity of the land in order to study the differences in crop responses in the two regions. Relationships between productivity and RU of different inputs in NE were significant $(P<0.1)$ while none of these relationships, with the exception of organic manure, were significant in $\mathrm{M}$ (Figure 2 and 3). According to the farmers surveyed and Kumaragamage (2010), one of the major limitations for the vegetable cultivation in $M$ was the moisture stress, because cropping pattern limits vegetable cultivation to Yala season where rainfall is less (Punyawardena, 2005). This could have masked the crop response to chemical fertilizers and liming in M. Higher uses of chemical fertilizers (Table 2) and extremely lower applications of organic fertilizers ( $<15 \% \mathrm{RU})$ could be some of the other reasons for lack of response to increasing levels of fertilizers. Compared to other field crops, vegetable crops returned very little amount of organic matter to the soil after harvesting and this together with low organic matter application could have degraded the agricultural lands over the last 50 or more years of intensive cultivation of vegetables in Marassana. Ketcheson (1980) concluded that the most serious long-term effect of intensive cultivation and monoculture on soil quality was deterioration in soil organic matter. Interestingly, productivity of the land has been responded significantly even to the small quantity of organic manure used (Figure. 2e) as also observed by Norris and Congreves (2018) in vegetable cropping systems of Canada. Therefore, it seems that there is an urgent need to encourage farmers in $\mathrm{M}$ to apply more organic matter into their cropping fields and also to make organic amendments available at a lower cost in order to increase land productivity and arrest further soil degradation.

Based on the fitted regression models, the RU of different fertilizers and amendments at which the maximum yield was recorded were calculated (Table 3). When usage of fertilizers or amendments by the vegetable farmers in NE increased towards the recommended levels, land productivity has significantly increased and maximum productivity had been observed around 75 to $90 \%$ of RU depending on the type of fertilizer or amendment. 

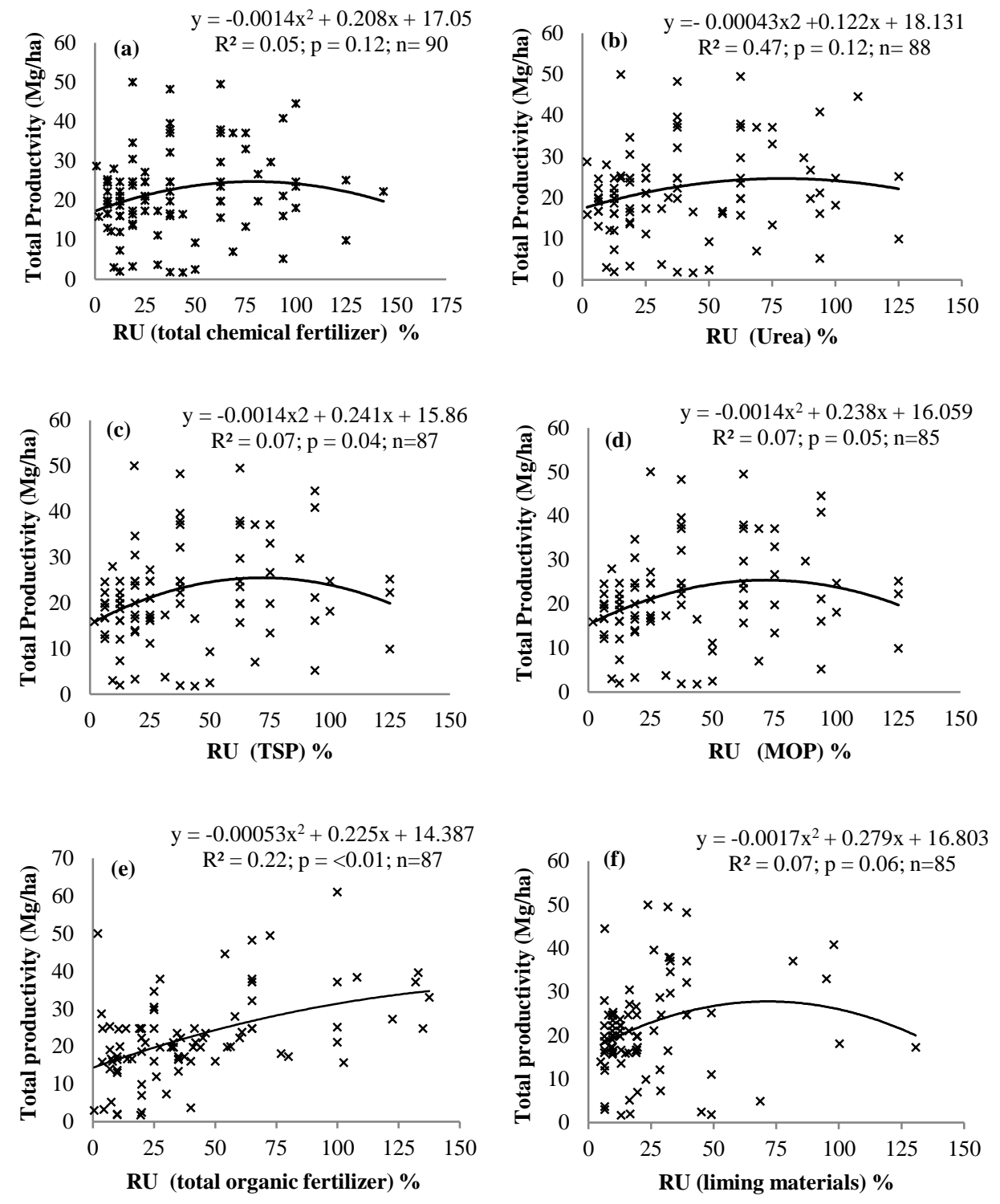

Figure 2. Relationship between the total land productivity and relative use (RU) of (a) total chemical fertilizer, (b) urea, (c) TSP, (d) MOP, (e) total organic fertilizer, and (f) liming materials by vegetable cultivating farmers in Nuwara Eliya region. The fitted regression model along with the $R^{2}, p$ value and $\boldsymbol{n}$ are also given within each graph 

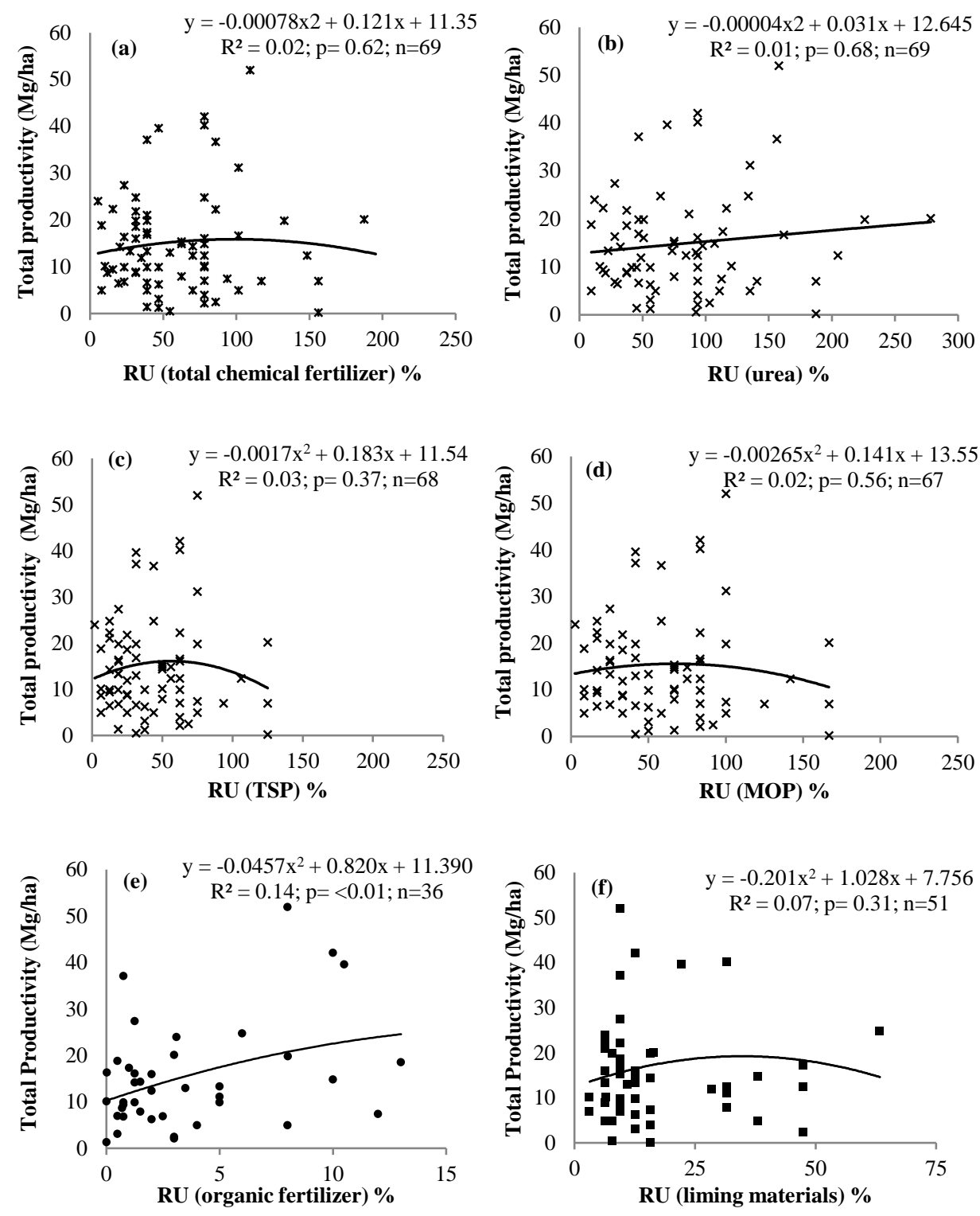

Figure 3. Relationship between the total land productivity and relative use (RU) of (a) total chemical fertilizer, (b) urea, (c) TSP, (d) MOP, (e) total organic fertilizer, and (f) liming materials by vegetable cultivating farmers in Marassana region. The fitted regression model along with the $R^{2}, p$ value and $n$ are also given within each graph

This suggests that about $40 \%$ of the farmers apply chemical fertilizers more than the crop requirement and about $50 \%$ of the farmers use TSP more than the requirement in NE (Table 2), but they do not obtain the maximum yields recorded by the farmers in the region. Therefore, there is an urgent need for promoting site-specific fertilizer management practices among intensively vegetable cultivating farmers in order to increase their productivity while 
minimizing soil degradation and environmental quality. Similar analysis could not be made for $\mathrm{M}$ because except for organic manure usage, the developed models for other fertilizers or amendments were not statistically significant.

Table 3. The level of fertilizer or amendment applied at the maximum productivity levels for different types of fertilizers and amendments in Nuwara Eliya and Marassana regions as calculated from the regression equations

\begin{tabular}{lcc}
\hline \multicolumn{1}{c}{ Fertilizer/ amendment (Mg/ha) } & Nuwara Eliya & Marassana \\
\hline Total chemical fertilizer & $74.3^{\dagger}$ & $77.6 \mathrm{~ns}$ \\
Urea & $141.8^{\dagger}$ & $>278 \mathrm{~ns}$ \\
TSP & $81.7^{*}$ & $53.8 \mathrm{~ns}$ \\
MOP & $80.4^{\dagger}$ & $26.6 \mathrm{~ns}$ \\
Total organic manure & $>137.3^{* * *}$ & $>9.01^{\dagger}$ \\
Liming materials & $87.2^{\dagger}$ & $39.3 \mathrm{~ns}$ \\
\hline$\dagger^{*} *, * * *-$ Regression models were significant at $P<0.1,0.05$ and 0.001, respectively. $n s-$ Not
\end{tabular}

\section{CONCLUSIONS}

Vegetable cultivation in the up-country in Sri Lanka is intensive where one to three cropping seasons in a given year is cultivated with different vegetables in rotation together with either potato or paddy, depending on the region, in the Maha season. Number of farmers who used excessive amounts of chemical fertilizers in their vegetable cultivations were higher in $\mathrm{M}$ when compared to that in NE. Majority of vegetable farmers in the two regions (70 to 100\%) applied only $<50 \%$ of the recommended levels of organic fertilizers and the situation was worse in the M. Mismanagement of fertilizers and amendments, together with the water scarcity, had resulted no significant productivity response to the added chemical fertilizers in $\mathrm{M}$. However, vegetable farmers in NE appears to obtain maximum productivity when the chemical fertilizers and lime were applied at around $70-90 \%$ of the recommended level, while productivity in both regions has increased with the increasing levels of organic fertilizers. We conclude that site-specific integrated soil fertility management strategies needs to be developed for the intensively cultivated vegetable farmers in up-country in Sri Lanka.

\section{REFERENCES}

Alliaume, F., Rossing, W.A.H., Garcia, M., Giller, K.E. and Dogliotti, S. (2013). Changes in soil quality and plant available water capacity following systems redesign on commercial vegetable farms, Europ. J. Agronomy. 46, 10-19.

Anon. (2007). Fertilizer recommendations for horticultural crops. Department of Agriculture, Peradeniya, Sri Lanka.

Anon. (2016). AgStat, Pocket book of Agricultural Statistics, 13, Socioeconomics and planning center, Department of agriculture, Peradeniya, Sri Lanka. 
Anon. (2015). Statistical abstract. Department of Census and Statistics, Colombo.

Ariyapala, W.S.B. and Nissanka, S.P. (2006). Reasons for an impacts of excessive fertilizer usage for potato farming in Nuwara Eliya District. Trop. Agric. Res. 18, 63-70.

Chen, Q., Zhang, X., Zhang, H., Christie, P., Li, X., Horlacher, D. and Liebig, H.P. (2004). Evaluation of current fertilizer practice and soil fertility in vegetable production in the Beijing region. Nutr. Cycl. Agroecosys. 69(1), 51-8.

Dassanayaka, R.A. and Hettiarachchi, L.S.K. (1999). Soils of the up country wet zone. pp.122-138. In: Mapa, R.B. Somasiri, S. and Nagarajh, S. (Ed.). Soils of wet zone of Sri Lanka: Morphology, characterization and classification. Soil Science Society of Sri Lanka.

Kendaragama, K.M.A. Lathief, M.A. and Chandrapala, A.G. (2001). Impact of vegetable cultivation in fertility status of soils in the NuwaraEliya area. ASDA. 3, 95-100.

Kendaragama, K.M.A. (2006). Crop growing environment in Sri Lanka with special emphasis on plant nutrient use. J. Soil Sci. Soc. Sri Lanka. 18, 1-18.

Ketcheson, J.W. (1980). Long range effect on intensive cultivation and monoculture on the quality of southern Ontario soils. Can. J. Soil. Sci. 60, 403-410.

Kumaragamage, D. (2010). Site specific nutrient management in soils of Sri Lanka: review of recent work using systematic approach to formulate fertilizer recommendations for annual crops. J. Soil Sci. Soc. Sri Lanka. 22, 1-15.

Kuruppuarachchi, D.S.P. (2010). Revive on the leaching of nitrate from agricultural soils and pollution of ground water in Sri Lanka. J. Soil Sci. Soc. Sri Lanka. 22, 37-50.

Lathief, M.A. and Maraikar, S. (2003). Studies on the performance of some vegetable crops in organic farming systems. ASDA. 5, 141-148.

Marikar, S., Wijewardena, J.D.H. and Amarasiri, S.L. (1996). Improving productivity of vegetable cultivation on Ultisols of Sri Lanka. pp.1-5. Symposium proceedings of managing soil fertility for intensive vegetable production systems in Asia. AVRDC. Tainan, Taiwan.

Norris, C.E. and Congreves, K.A. (2018). Alternative management practices improve soil health indices in intensive vegetable cropping systems: A Review, Front. Environ. Sci. 6, 50.

Punyawardena, B.V.R., (2005). Climate of the intermediate zone of Sri Lanka. pp 6-18. In: Mapa, R.B. Dassanayaka, R.A. and Nayakekorale, H.B. (Ed.). Soils of intermediate zone of Sri Lanka: Morphology, characterization and classification. Soil Science Society of Sri Lanka.

SAS Institute, Inc. (2003). SAS systems for Microsoft Windows. Released 9.1. SAS Institute, Inc. Cary, NC.

Senarath, A. and Dassanayaka, R.A. (1999). Soils of the mid country wet zone. pp 92-121. In: Mapa, R.B., Somasiri, S. and Nagarajh, S. (Eds.). Soils of wet zone of Sri Lanka: Morphology, characterization and classification. Soil Science Society of Sri Lanka. 
Sooriyagoda, L.D.B., Ranil, R.H.G., Dissanayaka, D.M.S.B. and Weerakkody, W.A.P. (2012). Sustainability of intensive vegetable farming in the Up-country region of Sri Lanka: A Situation Assessment. Chron. Horticult. 52, 13-17.

Weerahewa, J., Kodithuwakku S.S. and Ariyawardana, A. (2010). The fertilizer subsidy programme in Sri Lanka, Case Study No 7-11 of the Program: Food policy for developing countries. The role of government in the global food systems. Cornell University, Ithaca, NY

Wijewardhana, J.D.H. (1993). Effect of organic and chemical fertilizers on vegetable cultivation in Upcountry intermediate zone, Trop. Agriculturist.149, 1-11.

Wijewardhana, J.D.H. and Amarasiri, S.L. (1993). Response of vegetable crops in a cropping sequence to $\mathrm{K}$ and $\mathrm{Mg}$ fertilizers in the upcountry intermediate zone. Trop. Agriculturist. 149, 13-22.

Wijewardhana, J.D.H. (1995). Response of potato and vegetable crops grown sequentially to phosphorus application in an ultisols, Trop. Agriculturist. 150, 28-33.

Wijewardhana, J.D.H. and Amarasiri, S.L. (1997). Long term use of potassium fertilizer for vegetable crops in the upcountry intermediate zone. J. Natn. Sci. Coun. Sri Lanka. 25(1), 5968.

Wijewardhana, J.D.H. (1999). Contribution of Phosphorus and potassium from poultry manure application to potato and vegetables grown in an ultisols of the up country. ASDA. 1 , 129-136.

Wijewardhana, J.D.H. (2000a). Comparison of animal manure sources on potato and vegetable cultivation in the upcountry, ASDA. 2, 357-369.

Wijewardhana, J.D.H. (2000b). Sustainable plant nutrient management in intensive vegetable growing lands in the up country of Sri Lanka, J. Soil. Sci. Soc. Sri Lanka. 12, 1-13.

Wijewardhana, J. D. H., Yapa, U. W. S. P., Yatagama, S. M. K. G., (2001). Drinking water quality of some wells in the intensive vegetable growing lands in the upcountry wet zone. $\mathrm{J}$. Soil. Sci. Soc. Sri Lanka, 13, 14-22.

Wijewardhana, J. D. H. (2001a). Effect of sulphur and poultry manure application to vegetable crops. J. Soil. Sci. Soc. Sri Lanka, 13, 23-27.

Wijewardhana, J.D.H. (2001b). Fertilizer and soil amendments use on potato in relation to soil fertility in rice based cropping systems of upcountry of Sri Lanka, ASDA. 3,353-363.

Wijewardhana, J.D.H. (2001c). Effect of source and levels of liming materials on soil acidity in ultisols of the upcountry, ASDA. 3, 365-372.

Willekens, K., Vandecasteele, B., Buchan, D., De Neve, S. (2014). Soil quality is positively affected by reduced tillage and compost in an intensive vegetable cropping system. Applied Soil Ecology. 82, 61-71. 